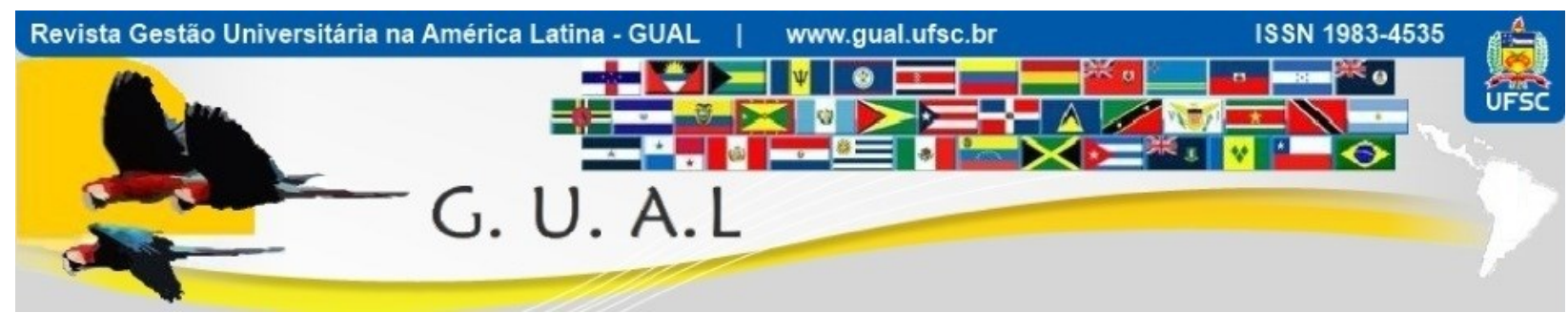

DOI: http://dx.doi.org/10.5007/1983-4535.2018v11n1p184

\title{
DE PROFESSOR A CHEFE DE DEPARTAMENTO: UM ESTUDO SOBRE O DESENVOLVIMENTO DAS COMPETÉNCIAS GERENCIAIS DESSES PROFISSIONAIS NUMA UNIVERSIDADE PÚBLICA
}

\section{FROM PROFESSOR TO ACADEMIC HEAD OF DEPARTMENT: A STUDY ABOUT MANAGERIAL COMPETENCE DEVELOPMENT OF THESE PROFESSIONALS IN A PUBLIC UNIVERSITY}

Diogo Reatto, Mestre Universidade Presbiteriana Mackenzie - UPM profdiogoreatto@hotmail.com

Janette Brunstein, Doutora Universidade Presbiteriana Mackenzie - UPM janette9@uol.com.br

Recebido em 17/abril/2016

Aprovado em 25/setembro/2017

Sistema de Avaliação: Double Blind Review

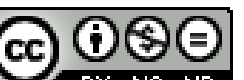

Esta obra está sob uma Licença Creative Commons Atribuição-Uso. 


\title{
RESUMO
}

Esta pesquisa qualitativa interpretativista básica responde a como professores da Faculdade de Odontologia de Araçatuba/UNESP desenvolvem suas competências gerenciais para atuarem como chefes de departamentos de ensino; e o que esses professores entendem por um chefe de departamento competente, ou seja, que concepção dão ao seu trabalho e quais conhecimentos mobilizam para a prática da sua função. As entrevistas semiestruturadas revelaram que o entendimento do trabalho pelos chefes é funcional, ou seja, supervisionar e controlar atributos técnicos da função, atuando como instrumentos burocráticos da gestão universitária. Os saberes teóricos limitam-se a conhecer as legislações da Universidade. Quanto aos saberes práticos, as rotinas administrativas poderiam ficar a cargo dos funcionários administrativos enquanto que as competências para o saber-agir são desenvolvidas por meio da observação das ações de colegas, pela experiência em funções anteriores e trajetória docente na Universidade. Os sentimentos e experiências no trabalho mais marcantes são cobrança por resultados e problemas nos relacionamentos interpessoais com docentes e técnicosadministrativos. A motivação para a gestão universitária é somente financeira. Os achados deste estudo contribuem teoricamente ao abandonar abordagens prescritivas e centrar sua discussão na imagem que o chefe de departamento constrói de si mesmo como gestor nas suas práticas sociais no trabalho.

Palavras-chave: Desenvolvimento de Competências. Universidade Pública. Chefe de Departamento de Ensino.

\begin{abstract}
This basic interpretative and qualitative research answers how professors from Dentistry School in Araçatuba/UNESP develop their management skills to act as university head of department, that is, what these professors understand by being a competent head of department and what knowledge they mobilize for the fulfillment of their function. The semistructured interviews revealed that the conception given to the job by the heads of departments is functional, that is, being a head of department means to supervise and control technical attributes. The theoric knowledge is limited to having knowledge of the laws of the University. As for the practical knowledge, the administration routines could be in charge of the administration staff while the skills for the know-how-to are developed by means of observation of the co-workers actions and through their past experiences at the University. The most outstanding psychological factors are demand for results and problems with personal relationships between professors and staff. The motivation for college administration is merely financial. The results of this study may contribute to the theory by abandoning prescriptive approaches and focusing their discussion on the image that the head of department builds about himself as a manager in their social practices at work.
\end{abstract}

Keywords: Competence Development. Public Universities. University Head of Department. 


\section{INTRODUÇÃO}

As universidades públicas contemporâneas assemelham-se cada vez mais às modernas organizações capitalistas, ambas acometidas por constantes e aceleradas mutações das novas tecnologias, escassez de recursos humanos e financeiros e alta competitividade (LAZARIN, 2008). No entanto, organizações privadas e públicas vivem em ambientes especiais caracterizados por seu ramo de atuação, ambiente social, cultural e político, nos quais estão inseridas. Por isso, essas organizações têm exigências diferentes quanto a competências (ODERICH, 2008). Logo, definir as competências gerenciais em instituições públicas de ensino superior constitui-se um desafio, seja pelo complexo contexto já descrito, seja pela necessidade de reinterpretação do que são competências para tais organizações.

Competência pode ser conceituada funcionalmente como habilidade de demonstrar desempenho superior numa determinada função (DELAMARE-LE DEIST; WINTERTON, 2005) ou, sob a abordagem interpretativista, como sendo o saber, o saber-fazer, o saber seragir e os recursos do ambiente mobilizados para gerar um desempenho (LE BOTERF, 2003). Competências, nessa perspectiva são fruto do entendimento que o indivíduo dá ao seu trabalho (SANDBERG; DALL'ALBA, 2006). Este estudo orienta-se na segunda perspectiva.

Dentro do cenário competitivo por aumento na produção científica, melhores titulações e obtenção de recursos de agências de fomento, professores se veem cada vez mais distante de sua prática em sala de aula (SMITH, 2002). Dentre outras inúmeras atividades que demandam cada vez mais capacidades diferentes de professores, está aquela de chefe de departamento, quando docentes se tornam administradores numa corrida para gerenciar contratos e projetos, orientar equipes e assistentes, chefiar grupos de técnicos, fazer inúmeras viagens, participar de comissões em agências governamentais e institucionais (KERR, 2005; SMITH, 2002) e incrementar a produção científico-acadêmica própria e de sua equipe. Apesar das exigências das universidades sobre o professor-gestor (SMITH, 2002), estudos empíricos sobre como professores tornam-se gestores em unidades universitárias são escassos na literatura (SMITH, 2002). Os trabalhos internacionais mais referenciados são os de Kerr (2005), Smith (2002) e Moses (1985). Já os nacionais são os de Silva e Cunha (2012) e de Silva, Moraes e Martins (2003), os quais focam a discussão gerencial na figura dos reitores e dos diretores universitários, ou incluem os coordenadores de curso como gerentes universitários (MARRA; MELO, 2005). Ainda há o estudo de Ésther, Silva e Melo (2010), o qual discute a construção das identidades de chefes de departamento no trabalho. Logo, não se 
encontrou nenhum trabalho referente a competências de chefes de departamento de ensino que abandone abordagens mais prescritivas e centre sua discussão na imagem que o chefe de departamento constrói de si mesmo como gestor e nas suas práticas sociais no trabalho. Esta é a lacuna que se pretende preencher.

Diante disso, este artigo propõe-se a conhecer, por meio de uma pesquisa qualitativa interpretativista, como professores da Faculdade de Odontologia do Câmpus de Araçatuba/UNESP desenvolvem suas competências gerenciais para atuarem como chefes de departamentos de ensino. Para tal, busca-se saber o que esses professores entendem por um chefe de departamento competente, ou seja, que concepção dão ao trabalho e quais conhecimentos mobilizam para a prática da sua função. Este artigo estrutura-se da seguinte forma: primeiro, discutem-se as abordagens do conceito de competências seguidas das competências individuais e gerenciais; na sequência, apresentam-se as formas de aprendizagem e desenvolvimento de competências gerenciais; a seção seguinte traz os procedimentos metodológicos e, por fim, os elementos de análise seguidos da conclusão.

\section{REFERENCIAL TEÓRICO}

\subsection{DIFERENTES ABORDAGENS DO CONCEITO DE COMPETÊNCIAS INDIVIDUAIS}

Esta seção resgata as linhas teóricas de discussão sobre o polissêmico conceito de competências para compreender o entendimento dos sujeitos de pesquisa sobre este construto.

As diversas definições dadas ao conceito de competência geraram certa confusão no debate do que elas realmente são a ponto de ser muito difícil chegar-se a uma definição comum que abarque todas as diferentes formas de como o termo é usado (DELAMARE-LE DEIST; WINTERTON, 2005). Seu entendimento dependerá do uso que se faz de competências, isto é, a serviço de quê ou de quem estão os conceitos, bem como dos propósitos do estudo e da visão que se tem de competências (PARRY, 1996).

A visão americana, caracterizada pelos estudos de White (1959), McClelland (1973), Boyatzis (1982) e Spencer e Spencer (1993), considera competências como características ou habilidades de um indivíduo as quais o permitem demonstrar ações apropriadas que o levem a um desempenho superior no trabalho. Essa definição funcionalista, sustentada por traços pessoais para a garantia de um desempenho superior no cargo, vem sendo criticada por produzir descrições de competências genéricas e abstratas (SANDBERG, 2000). 
A visão anglo-saxônica parte de uma lista fixa de competências a serem alcançadas para conferir desempenho superior num determinado cargo. Assim, competência é entendida como a capacidade de aplicar conhecimento, entendimento e habilidade de acordo com os requisitos ocupacionais padrões do cargo ou área de atuação (DELAMARE-LE DEIST; WINTERTON, 2005), ignorando comportamentos pessoais destacados na visão americana.

As abordagens multidimensional e holística vêm como uma resposta às abordagens racionalistas anteriormente descritas neste texto. A principal crítica é que competência humana não pode se restringir à descrição de um conjunto de atributos que trabalhadores devem alcançar em seus empregos, desconsiderando o contexto em que estão inseridos (SANDBERG, 2000). A partir das críticas ao modelo norte-americano e funcionalista inglês, propostas alternativas emergem pela busca de modelos mais compreensivos de competências (SANDBERG, 2000; DELAMARE-LE DEIST; WINTERTON, 2005), como a abordagem interpretativista, na qual a competência não separa indivíduo do seu trabalho; ao contrário, trabalhador e trabalho são vistos como uma única entidade marcada pelas experiências vividas no trabalho. Competência é constituída, então, pelo significado que o trabalho tem para aquele indivíduo (SANDBERG, 2000). Para Sandberg e Dall'Alba (2006), competências não são constituídas por um conjunto de conhecimentos, habilidades e atitudes isolado no trabalho, senão organizado para ser aplicado dentro de um contexto específico. Logo, desenvolver competências, para os autores, é mudar o entendimento do que é trabalho para um indivíduo para, assim, dar forma a sua competência (BITENCOURT et al., 2013). É baseado nessa abordagem que se conduz este trabalho.

\subsection{DAS COMPETÊNCIAS INDIVIDUAIS ÀS COMPETÊNCIAS GERENCIAIS DE CHEFES DE DEPARTAMENTO}

É importante discutir competências individuais já que influenciam o desenvolvimento das competências dos grupos e das organizações. As competências gerenciais são uma categoria de competências individuais que mobilizam recursos para o desenvolvimento das outras dimensões de competências: as essenciais (relacionadas à diferenciação organizacional diante de concorrentes), as funcionais (específicas de cada uma das áreas vitais da empresa) e até mesmo as próprias individuais (RUAS, 2001; BITENCOURT et al., 2013).

Nas universidades, o chefe de departamento de ensino é o manager-academics, ou aquele responsável por entregar um currículo acadêmico à universidade e ainda prover liderança e gestão aos docentes e pessoal administrativo (MOSES, 1985; SMITH, 2002). O 
bom desempenho nesta dualidade de papéis é essencial ao chefe de departamento, pois como manager-academics, é ele o indivíduo que traduzirá as estratégias da diretoria em planos operacionais para que o departamento alcance os objetivos de representar a excelência acadêmica da universidade (MOSES, 1985; SMITH, 2002; LEITE, 2011). Cabe-lhe, ainda, a responsabilidade de solicitar contratação de recursos materiais e humanos; administrar conflitos internos (com funcionários, pares e discentes) e externos (com clientes, agências de fomento, pacientes); acompanhar os resultados obtidos; analisar e tomar decisões dentro de seu âmbito de atuação. É de sua responsabilidade, também, orientar e apoiar o desenvolvimento profissional dos membros de sua equipe (LEITE, 2011).

No entanto, Moses (1985) explica que professores universitários e administradores têm visão diferente sobre a gestão acadêmica. Enquanto estes zelam por clareza na especialização do trabalho e na hierarquização das responsabilidades, aqueles trabalham num ambiente em que as decisões são tomadas num colegiado; a divisão do trabalho não é tão simples, pois muitos dão aulas de graduação, alguns de pós-graduação, e outros também pesquisam; as linhas de responsabilidades não são nítidas e a liberdade pessoal e acadêmica nestes departamentos de ensino interfere na hierarquia das responsabilidades. Dessa forma, o chefe de departamento deve reunir competências que lhe permitam entregar excelência gerencial à universidade, apesar de seus poderes limitados e muitos afazeres (MOSES, 1985).

É diante dessas enormes exigências do papel de chefe e das diferenças de estrutura e sistemas sociopolítico e cultural das universidades que o desenvolvimento de competências e a criação de categorias de novas competências gerenciais se constituem um desafio (ODERICH, 2008). Nesse sentido, a abordagem fenomenológica proposta por Sandberg (2000) procura compreender por que determinados atributos são mais relevantes que outros na atuação gerencial. A especificidade para compor o conjunto mais apropriado de atributos que são mobilizados a partir da compreensão do trabalho gerencial para cada organização implica o desenvolvimento por competências a partir de um diagnóstico da situação organizacional e do próprio significado que seus gerentes dão ao trabalho (MOURA; BITENCOURT, 1996).

A mudança nas concepções de trabalho é a forma mais básica de desenvolvimento de competências e tem como forma de suporte o ciclo de competências de Sandberg (2000). Outra forma de compreender o desenvolvimento desse conjunto de competências gerenciais é por meio da aprendizagem organizacional enquanto processo social. Ambos serão melhor fundamentados na próxima seção. 


\subsection{A APRENDIZAGEM DE COMPETENNCIAS GERENCIAIS COMO PROCESSO SOCIAL}

A aprendizagem social enxerga a aprendizagem como processo que não acontece apenas na mente do indivíduo, senão que deriva da participação dele em atividades sociais no trabalho como membro da organização e das práticas que a sustentam (GHERARDI; NICOLINI, 2001). O professor-gestor constrói-se nesse processo social de interação cotidiana com os membros de seu departamento, sejam eles docentes ou técnicos-administrativos, com especial atenção à aprendizagem informal no local de trabalho (SMITH, 2002).

A aprendizagem gerada dessa prática cotidiana, de caráter informal e implícito, é fundamental, pois grande parte do que é útil para o desempenho no trabalho tem como origem tentativas e erros, conhecimento transferido por meio de histórias contadas e observação de pessoas experientes por aprendizes (LEITE, 2011). O professor-gestor ainda aprende das experiências vivenciadas ao longo da sua trajetória pessoal e profissional (MOSES, 1985; SMITH, 2002). Além da aprendizagem baseada na vivência de gestores, a aprendizagem experiencial pressupõe que só ocorre aprendizado quando uma pessoa é capaz de refletir sobre suas ações, reorganizando e reconstruindo suas experiências, como um processo que envolve busca, teste e avaliação de entendimentos intrínsecos à experiência e prática profissional (CLOSS; ANTONELLO, 2011). De acordo com Cunliffe (2004), a reflexão é importante para a educação gerencial porque permite que gestores pensem criticamente a respeito dos seus conceitos e ações, sendo possível, assim, desenvolver formas mais colaborativas, responsáveis e éticas de se gerir a organização. Para Sandberg e Dall'Alba (2006), o uso da autorreflexão é um meio de desenvolver competências na medida em que o gestor se distancia do seu desempenho no trabalho e reflete sobre ele, aumentando sua compreensão sobre seu trabalho.

Devido às diversas maneiras expostas anteriormente pelas quais o professor-gestor pode construir sua competência e não se limitando somente a essas, é necessário desenvolver uma abordagem que permita a competência gerencial ser construída como um processo de tornar-se e não de ser um gestor competente, porque tornar-se competente sugere que competência não é algo fixo ou um estado final, mas que significa aprender como ser competente diante de cada nova situação de interação social no ambiente de trabalho (McKENNA, 1999). Assim, o ciclo de competências proposto por Sandberg (2000) e representado por Bitencourt et al. (2013) na Figura 1 apresenta-se como uma maneira de compreender a concepção do trabalho como origem das competências. No caso deste estudo, 
compreender a concepção que o professor-gestor dá à função de chefe de departamento contribui para compreender as bases sobre a qual constroem sua competência como gestor. Cada componente do modelo pode variar de forma, conteúdo e importância de acordo com a concepção que o chefe de departamento dá ao seu trabalho. O conteúdo dos componentes é agregado à trajetória do chefe, influenciando seus saberes, sua ação e, talvez, sua concepção do trabalho. Assim, a concepção é criada, recriada, transformada e compartilhada nas práticas de trabalho dentro do departamento e da universidade.

Figura 1 Ciclo de Competências de Sandberg (2000)

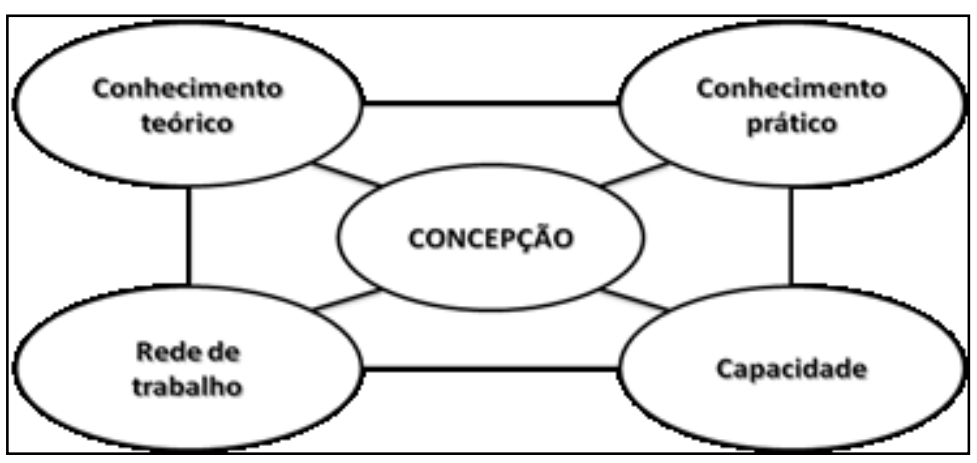

Fonte: Bitencourt et al. (2013, p. 169)

Para Sandberg (2000), a concepção que o gestor dá ao trabalho é o ponto de partida para que ele mobilize: os conhecimentos teóricos - características intelectuais que ele julga necessário conhecer; os conhecimentos práticos - sua habilidade de fazer, executar seu trabalho; a rede de trabalho: interação com outras pessoas no ambiente de trabalho e acesso a manuais, legislação e bases de dados usados no trabalho; a capacidade: aspectos físicos como volume de trabalho e aspectos psicológicos relacionados a sentimentos ou experiências pessoais no sentido de ser uma pessoa competente que pode alcançar resultados (BITENCOURT et al., 2013). Dessa forma, a definição das competências necessárias ao chefe de departamento dependerá da sua visão sobre o que é ser chefe de departamento e da sua boa vontade de se desenvolver como manager-academics (SMITH, 2002). A seção seguinte apresenta a natureza da pesquisa e descreve seus procedimentos metodológicos. 


\section{PROCEDIMENTOS DE INVESTIGAÇÃO}

Esta pesquisa foi planejada para responder aos questionamentos: como professores da Faculdade de Odontologia do Câmpus de Araçatuba/UNESP (FOA/UNESP) desenvolvem suas competências gerenciais para atuarem como chefes de departamentos de ensino? Esta questão se desmembra em outras duas: 1) O que esses professores entendem por um chefe de departamento competente, ou seja, que concepção dão ao trabalho? 2) Quais conhecimentos mobilizam para a prática da sua função?

A escolha da faculdade definiu-se pela relevância da Universidade no cenário científico-acadêmico do estado de São Paulo, possibilidade de comparar os achados deste estudo com as demais unidades e pela facilidade de acesso ao campo. Quanto ao roteiro de entrevistas, iniciava-se com questões que permitiam a narrativa da formação e da trajetória acadêmico-profissional do professor. Os principais eixos de discussão baseavam-se na concepção do chefe de departamento sobre o que é sua função, o que é ser um chefe de departamento competente, quais são os saberes que ele julgava necessários ter para ser chefe de departamento e como foi seu desenvolvimento para assumir a função. Ainda, solicitou-se a descrição de situações nas quais os entrevistados colocaram em prática as competências citadas como necessárias para ser chefe de departamento.

Para responder ao problema de pesquisa, conduziu-se um estudo qualitativo interpretativo básico (MERRIAM, 1998). A abordagem paradigmática da pesquisa foi a interpretativista (GEPHART, 2004). Os sujeitos de pesquisa entrevistados foram 6 chefes de departamentos de ensino, identificados neste estudo pela sigla $\mathrm{ChD}$, da Faculdade de Odontologia de Araçatuba - FOA/UNESP, sendo 4 homens e 2 mulheres, casados, de idade entre 40 e 47 anos. Sobre o vínculo trabalhista, 5 professores são autárquicos e 1 celetista, e todos são contratados sob Regime de Dedicação Integral à Docência e à Pesquisa - RDIDP com obrigação contratual de cumprimento de 40 horas de trabalho semanais. A titulação mínima é de doutor (4 livre-docentes e 2 doutores) e o tempo de trabalho na faculdade varia de 1 ano e 3 meses a 25 anos. O tempo na função de chefe de departamento varia de 5 meses a 4 anos. Todos os chefes se graduaram em Odontologia na FOA e, à exceção do ChD4, iniciaram suas carreiras acadêmicas como docente também nessa Faculdade. O ChD4 foi o único que atuou como docente em instituições de ensino privadas e, concomitantemente, exerceu cargo de cirurgião-dentista na iniciativa privada. 
Quanto à experiência em outros cargos anteriores à chefia departamental, todos exerceram a vice-chefia por uma ou duas vezes, exceto o ChD4, que exerceu cargos de coordenação de curso de graduação e de pós-graduação externos à FOA/UNESP. Os ChD1 e ChD3 atuaram como coordenadores de curso de graduação e de pós-graduação locais.

As informações foram coletadas por meio de entrevistas semiestruturadas (FLICK, 2009), as quais ocorreram no próprio ambiente de trabalho de cada chefe de departamento, com duração entre 40 e 80 minutos. Os sujeitos de pesquisa foram antecipadamente informados sobre os objetivos da pesquisa e, voluntariamente, aceitaram participar, assinando um Termo de Consentimento Livre e Esclarecido - TCLE - sobre os objetivos da pesquisa e da confidencialidade das informações e permitindo a gravação da entrevista. O conteúdo das entrevistas foi categorizado seguindo a estratégia de análise de dados qualitativos categorial adaptado de Flores (1994) de acordo com os componentes do modelo de desenvolvimento de competências de Sandberg (2000).

\section{APRESENTAÇÃO E ANÁLISE DOS RESULTADOS}

As categorias de análise dos dados qualitativos das entrevistas representadas na Figura 2 foram definidas a priori, pois estão baseadas no Ciclo de Competências de Sandberg (2000) representado anteriormente na Figura 1. São elas: $1^{a}$ ) Entendimentos da função de chefe de departamento de ensino; $2^{\mathrm{a}}$ ) Saberes teóricos para atuação como chefe de departamento de ensino; $3^{\text {a }}$ ) Saberes práticos para a atuação como chefe de departamento de ensino; $4^{\text {a }}$ ) As pessoas como acesso ao conhecimento no trabalho; $5^{\text {a }}$ ) Sentimentos e experiências no trabalho. As categorias definidas a posteriori, oriundas de dados que se revelaram nas entrevistas, são: $1^{\mathrm{a}}$ ) $\mathrm{O}$ conceito de competência para o chefe de departamento; $2^{\mathrm{a}}$ ) A quem cabe a gestão do departamento de ensino? 
Figura 2 Sistema de categorias de análise dos dados

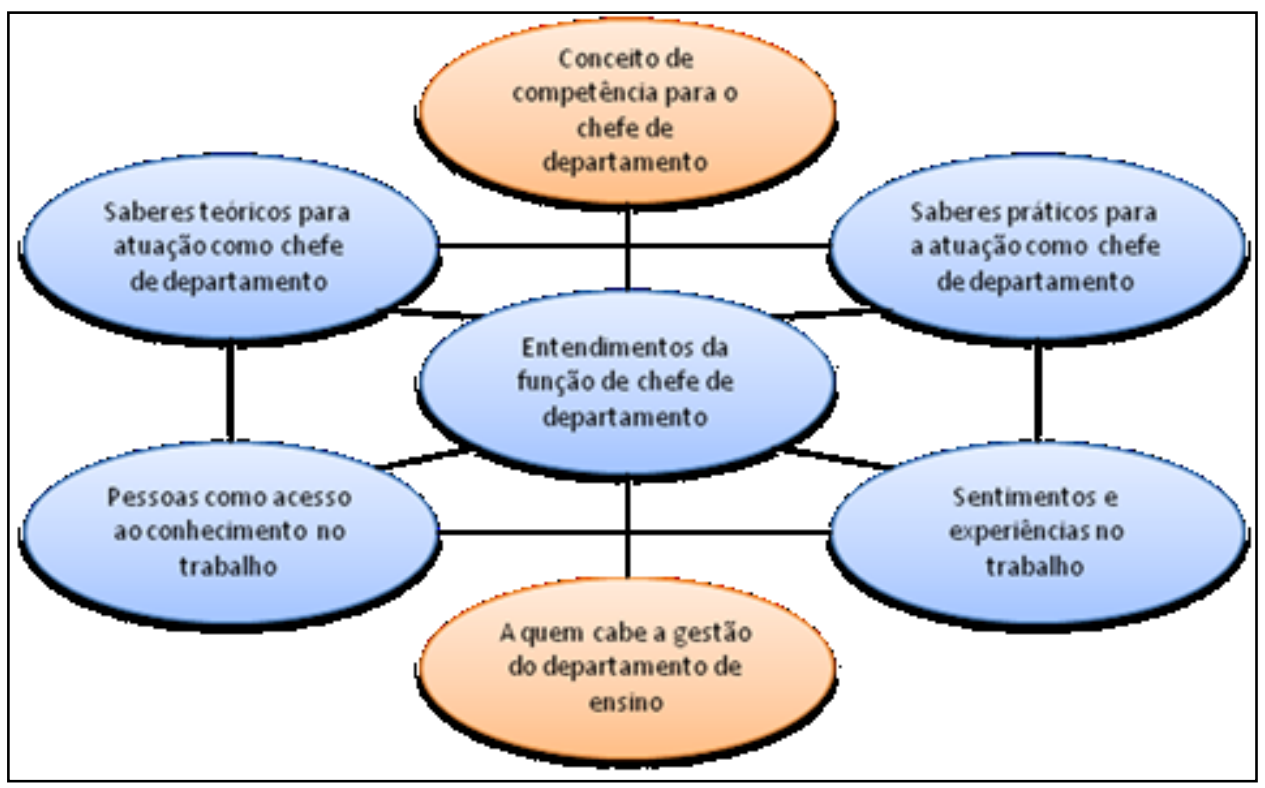

Fonte: elaborado pelos autores a partir de dados primários (2013).

\subsection{ENTENDIMENTOS DA FUNÇÃO DE CHEFE DE DEPARTAMENTO DE ENSINO}

Os sujeitos $\mathrm{ChD2}$, ChD3, ChD5 e ChD6 têm uma visão funcional de seu trabalho. Para todos eles, o ser chefe de departamento restringe-se a cumprir e cobrar o que consta na descrição de cargo da UNESP. É supervisionar, controlar, ser meramente um instrumento burocrático da gestão. "É seguir o que a UNESP manda fazer. Há lá a descrição do cargo e a gente segue aquilo. É tranquilo, é burocrático. É cumprir sua função” (ChD6).

Para o ChD5, o gestor não deve e nem pode controlar as pessoas, pois não consegue mudá-las: "Para mim é muito tranquilo [ser chefe]. É deixar todo mundo trabalhar à vontade, cada um fazendo o seu papel. Eu não sou de ficar me intrometendo no que o pessoal está fazendo" (ChD5). Em contrapartida, os $\mathrm{ChD1}$ e ChD4 atribuem visão mais holística à função. Em seu relato, o ChD1 exerce o papel de agente integrador, de líder, de interlocutor, de tradutor das necessidades do grupo, ademais de pensar nos grupos de interesse: "Nós temos estrutura, temos várias agências de fomento que estão nos alicerçando em cima disso, então, ser um chefe de departamento numa unidade de ensino é exatamente focar isso: lá na frente, o que a gente vai querer do nosso departamento mediante a filosofia da universidade e como você vai dar sua parcela de contribuição" (ChD1). O ChD4 destaca, ainda, a importância de se desenvolver um perfil de chefe de departamento de ensino democrático e carismático, pois a liderança não é algo que lhes é ensinado dentro da organização. 
Dessa forma, os chefes de departamento de ensino entendem seu trabalho basicamente de duas formas diferentes: como cumprimento das atividades de controle do pessoal docente e técnico-administrativo, e como o entendimento da função como o elo entre o desenvolvimento organizacional e o das pessoas, o que vai ao encontro da difícil dualidade de papéis descrita por Smith (2002) em que afirma que o chefe de departamento é um líder acadêmico e, ao mesmo tempo, um gerente de linha. Partindo da afirmação de Sandberg e Dall’Alba (2006) de que a forma pela qual o indivíduo entende o trabalho é o início para que ele mobilize os conhecimentos, as habilidades e as atitudes para um trabalho competente, as quatro próximas seções apresentam quais saberes os chefes julgam ser necessários para dar sentido às suas concepções do trabalho.

\subsection{SABERES TEÓRICOS PARA ATUAÇÃO COMO CHEFE DE DEPARTAMENTO DE ENSINO}

Os sujeitos informaram que, para atuar como chefe de departamento, aprenderam as suas atribuições já no exercício do cargo, sob o respaldo das legislações que regem o funcionamento da universidade. Embora todos tenham buscado por iniciativa própria os instrumentos legais que necessitavam, o ChD2 acredita que seria função da área de Recursos Humanos dar-lhe o treinamento devido para atuar como dirigente de departamento.

Já os ChD3 e 4 são os únicos a defender que muitos conhecimentos teóricos de como ser chefe podem vir da aprendizagem formal, ou seja, de cursos e treinamentos, os quais poderiam versar sobre gestão e relacionamento pessoal. Smith (2002) observou que o conhecimento sobre relacionamento pessoal é o de maior dificuldade para os chefes de departamento pesquisados, agravado pelo poder limitado e falta de suporte da direção da faculdade/universidade. Porém, o ChD4 adverte que a parte administrativa se aprende. No entanto, os relacionamentos interpessoais e a inteligência emocional exigem esforços contínuos de aperfeiçoamento e que não há cursos para isso.

Para o ChD5, não há a necessidade de nenhum conhecimento teórico prévio, porque "naturalmente, as experiências que você vai tendo no cotidiano vão lhe alimentando aos poucos. Na prática" (ChD5). Ou o que se precisa saber pode ser esclarecido perguntando-se aos funcionários técnicos-administrativos da administração central (ChD6). Assim, percebe-se que os chefes de departamento, em sua maioria, não valorizam ou não percebem a necessidade de educação formal na área de gestão para atuarem como chefe de departamento de ensino, limitando suas necessidades de conhecimentos teóricos ao conhecimento da 
legislação da UNESP. No entanto, notam que "ser chefe atualmente não é como ser chefe no passado" (ChD3), as situações profissionais às quais são submetidos são muito mais complexas hoje, seja pela própria descrição da função de chefe prevista no Estatuto da UNESP, que é generalista, seja pelas demandas externas de órgãos de fomento à pesquisa e de controle educacional como o MEC e a CAPES.

Assim, como afirma Le Boterf (2003), "o profissional é aquele que sabe administrar uma situação profissional complexa" e que não necessariamente precisa possuir conhecimentos, senão que precisa saber mobilizá-los quando diante de um problema a ser resolvido. Logo, a afirmação dos ChD5 e 6 de que não precisam ter conhecimentos profundos em gestão não seja tão despropositada assim, pois da mesma forma afirmam saber a quem perguntar quando precisam, o que revela a capacidade de mobilizar as pessoas certas diante de situações complexas.

Smith (2002) e Moses (1985) identificaram a falta de treinamento adequado ou a inexistência da descrição de cargo como fontes de origem de dificuldade na atuação como chefe de departamento. Mesmo quando houve uma detalhada descrição do cargo, os chefes entrevistados por Smith (2002) unanimemente afirmaram que ela era inútil, sendo os acordos informais feitos com os pares e com o pessoal administrativo mais úteis no ambiente dinâmico da universidade. A descrição do cargo de chefe de departamento na UNESP mostra o "o que" o chefe de departamento deve fazer. Já o "como" se deve fazer, este fica a cargo das competências que cada docente-gestor mobiliza segundo sua visão do que é ser chefe de departamento. Talvez isso explique porque para os sujeitos de pesquisa de Smith (2002) uma descrição de cargo pode ser não muito útil. Quanto aos treinamentos formais, os sujeitos de pesquisa de Smith (2002) ressaltam que são essenciais desde que sejam desenvolvidos especificamente para as suas necessidades como chefe de departamento e que reflitam a complexidade do papel deste professor-gestor. Talvez, devido às especificidades da gestão universitária, o conteúdo dos cursos de gestão oferecidos pelas instituições de ensino esteja distante da realidade dos chefes de departamento, o que os leva a valorizar mais a aprendizagem pela experiência. Smith (2002) acredita que a universidade tem a missão de educar e treinar, no entanto, paradoxalmente, não investe no desenvolvimento de seu próprio pessoal. 


\subsection{SABERES PRÁTICOS PARA A ATUAÇÃO COMO CHEFE DE DEPARTAMENTO} DE ENSINO

A observação da atuação de outros professores na chefia do departamento foi considerada a principal forma de aprendizagem da função. Exceto o $\mathrm{ChD} 4$, que não exerceu vice-chefia na FOA/UNESP, todos os demais declaram que a vice-chefia pouco os ajudou na compreensão do que é a função de chefe, pelo fato de as funções do vice-chefe serem somente as de substituir o chefe em sua ausência, o que limita a sua atuação à observação das ações, atitudes, comportamentos e postura do chefe no local de trabalho. O chefe em exercício evita delegar suas funções ao seu vice também por questões financeiras, uma vez que o vice-chefe só recebe a gratificação referente à função nos períodos de férias ou licenças do chefe.

Ainda dos relatos, depreendem-se outras formas de aprendizagem como o aprender com os outros colegas (ChD2), com o conhecimento do histórico e da trajetória da organização (ChD1), tentativa e erro (ChD5) e a experiência em cargos gerenciais anteriores (ChD1, 2 e 3), o que sugere a existência de reflexão no processo de aprendizagem e de desenvolvimento de competências necessárias para atuar como chefe de departamento.

A reflexão é necessária para que a mente faça conexões entre acontecimentos, produzindo novos insights e experiências (KOLB, 1984). "Eu via o que eles faziam e observava: isso não deu certo. Eles fizeram e não agradou. Então, não poderei fazer isso. Quando eu fui assumir a chefia, eu já estava preparado para isso" (ChD3). Os chefes reflexivos devem ter respeito pela história, não somente dos fatos marcantes, mas daqueles que ocorrem no dia-a-dia (LEITE, 2011), tendem a prestigiar a trajetória profissional e o histórico organizacional, porque percebem que o conhecimento deles foi construído como um processo - knowing - criado na interação com os colegas de trabalho e na prática cotidiana do gestor (GHERARDI; NICOLINI, 2001; CLOSS; ANTONELLO, 2011).

Os chefes de departamento da FOA/UNESP dão ênfase à prática e suas ações atuais são influenciadas por suas experiências passadas. Relatos idênticos foram identificados no estudo de Silva, Moraes e Martins (2003), com diretores das unidades universitárias da Universidade Federal de Santa Catarina.

Le Boterf (2003) alerta que mais importante que saber fazer é o saber agir, ou o saber o que fazer num determinado contexto. Enquanto que o saber fazer é o mais elementar grau da competência, o saber o que fazer é saber tomar iniciativas e decisões, negociar e arbitrar, fazer 
escolhas, assumir riscos, reagir a contingências, inovar, assumir responsabilidades, tudo diante de um cenário complexo de atuação do profissional.

A própria evolução do ambiente organizacional tem forçado esses profissionais a procurarem formas de desenvolverem saberes práticos antes não necessários a sua atuação. Como já relatado, o cenário de atuação do chefe atualmente difere em complexidade ao do passado. Todos os chefes citaram suas experiências com as novas práticas de Recursos Humanos implementadas pela Universidade, em especial com o ADP - Sistema de Acompanhamento e Desenvolvimento Profissional da UNESP - o qual é o sistema de avaliação de desempenho dos funcionários técnico-administrativos da UNESP, como oportunidade para desenvolverem questões ligadas ao relacionamento interpessoal com os funcionários técnico-administrativos. Enquanto o ADP desenvolve o saber-agir dos chefes de departamento, o saber-fazer fica a cargo das secretárias de departamento. Todavia, a função da secretária no entendimento dos chefes reflete exatamente a concepção funcional que dão ao seu trabalho como chefe de departamento, ou seja, de que a secretária, ao exercer rotinas administrativas eficientemente, acaba esgotando as funções do chefe.

Como fatores que catalisam o desenvolvimento dos saberes práticos, citaram-se a iniciativa para agir e a curiosidade em aprender. Para Le Boterf (2003), a competência existe quando se sabe encarar o imprevisto e o indivíduo se antecipa aos acontecimentos.

Mesmo com os fatores identificados para mobilização do saber-agir, pode-se passar pela experiência ser chefe e o indivíduo não conseguir refletir após a ação, gerando discursos de indiferença diante da experiência: "O pessoal [outros chefes] diz que aprendeu muita coisa [...] de administração, que foi muito bom pra vida dele. Para mim eu acho que não. [...] Para mim, ter sido chefe ou não ter sido chefe foi indiferente" (ChD5). É somente refletindo sobre seu trabalho que o chefe poderá mudar sua concepção da função e mobilizar os atributos necessários para desenvolver competências (SANDBERG, 2000).

\subsection{AS PESSOAS COMO ACESSO AO CONHECIMENTO NO TRABALHO}

Em sua maioria, os contatos pessoais e não-pessoais que os chefes de departamento relataram acessar para maximizar os seus saberes teóricos e práticos limitam-se aos funcionários administrativos da Diretoria da Faculdade e das divisões acadêmica e administrativa. Tais funcionários são responsáveis pela execução das atividades-meio da Faculdade e são consultados pelos chefes em caso de dúvidas com as legislações que orientam 
o trabalho na UNESP. Os sistemas informatizados que vêm gradualmente sendo implantados pela Universidade na tentativa de padronizar o trabalhos dos campi e construir uma base sólida e confiável para consulta a dados administrativos e científico-acadêmicos diminuem a dependência de informações dadas pelos funcionários administrativos. Por isso, conhecer as redes de trabalho, sejam elas informatizadas (não-pessoais) ou não (pessoais) e saber mobilizá-las na hora certa demonstra a competência do profissional (LE BOTERF, 2003; SANDBERG; DALL'ALBA, 2006): "Não tem como você sozinho conseguir resolver todos os problemas. Nossa universidade é muito complexa. Ela tem uma legislação muito bem definida, porém, há situações que tem particularidade, que precisamos de manobras administrativas para funcionar. Nesse momento, se é uma pessoa que tem livre acesso, se tem um contato bom com as pessoas do administrativo, como eu tenho... isso ajuda muito" (ChD1). O relato exposto exemplifica que a capacidade do profissional é função do seu poder de acesso e de sua capacidade de tratamento relativo a uma rede de conhecimentos disponível.

\subsection{SENTIMENTOS E EXPERIÊNCIAS NO TRABALHO COMO CHEFE DE DEPARTAMENTO DE ENSINO}

A capacidade, dentro do ciclo de competência proposto por Sandberg (2000), refere-se aos aspectos físicos e psicológicos experienciados pelos chefes de departamento no ambiente de trabalho para a consecução dos objetivos. Dentre os aspectos físicos, não foi a quantidade de trabalho, senão a sua complexidade o fator mais abordado por todos os chefes. Para eles, os desafios encontram-se na cobrança por resultados acadêmicos, administrativos e, especialmente, os científicos. $\mathrm{Na}$ gestão do departamento, o mandato de 2 anos, com possibilidade de mais um mandato por igual período, é uma barreira, pois não se conseguem estabelecer planejamentos de longo prazo e não se dá continuidade a projetos anteriores. Os mesmos aspectos de quantidade de trabalho, sua complexidade e impossibilidade de planejamento a longo prazo foram encontrados nos estudos de Moses (1985) e Smith (2002).

A maior ênfase recai sobre os aspectos psicológicos que envolvem os problemas de relacionamento interpessoal entre os servidores dos departamentos, sejam eles docentes ou técnicos-administrativos, e a avaliação de desempenho dos técnico-administrativos. As experiências vividas pelos chefes de departamento referente a esses dois momentos marcaram o discurso dos seis entrevistados. Da mesma forma, os chefes de departamento dos trabalhos de Moses (1985) e Smith (2002) atribuem às habilidades interpessoais, à capacidade de boa 
comunicação e à atuação como "advogado" ou mediador do departamento como sendo as competências mais importantes para a atuação como professor-gestor.

Quanto às formas de lidar com as dificuldades nos relacionamentos interpessoais, estas vão desde a tentativa de integrar dos $\mathrm{ChD} 1$ e 4, a de intervir do ChD2 e 3, e a de se ausentar dos ChD5 e 6. Para o ChD1, a conversa franca e a negociação são os pontos-chave para atenuar os problemas de relacionamento e alcançar os objetivos de seu departamento. Já o ChD3 acrescenta que a agenda sobrecarregada dos docentes, suas salas estarem divididas em diversos prédios dentro da Faculdade e suas necessidades estarem acima dos interesses organizacionais são impedimentos para ações integradoras e minimizadoras de problemas de relacionamento. Por sua vez, características escapismo de conflitos e minimização de problemas também estão presentes nos sujeitos entrevistados. Para os ChD5 e 6, os problemas devem ser resolvidos por quem os causou, não tendo o chefe de se preocupar com situaçõesproblema de alunos e professores. Para esses chefes, o saber-agir para os problemas de relacionamentos interpessoais é não agir. A reação a tais confrontos deve ser a nãointervenção, a descentralização das ações corretivas e preventivas a quem criou o problema.

Uma vez apresentadas e discutidas as concepções que cada chefe de departamento da FOA/UNESP dá ao seu trabalho, bem como os saberes e as redes de contatos que mobilizam e os aspectos físicos e psicológicos representados nas experiências vividas no trabalho, o quadro 1 apresenta uma síntese dos resultados das análises deste trabalho. 
Quadro 1 Concepção dada ao trabalho pelos Chefes de Departamento de Ensino e os saberes mobilizados

\begin{tabular}{|c|c|c|c|c|c|}
\hline Sujeito & $\begin{array}{c}\text { Entendimento } \\
\text { da função de } \\
\text { chefe }\end{array}$ & $\begin{array}{l}\text { Saberes } \\
\text { teóricos }\end{array}$ & $\begin{array}{l}\text { Saberes } \\
\text { práticos }\end{array}$ & $\begin{array}{l}\text { Pessoas como acesso } \\
\text { ao conhecimento }\end{array}$ & $\begin{array}{c}\text { Sentimentos e } \\
\text { experiências no trabalho }\end{array}$ \\
\hline ChD1 & $\begin{array}{c}\text { Multidimensio } \\
\text { nal }\end{array}$ & $\begin{array}{l}\text { Limitados } \\
\text { à } \\
\text { legislação } \\
\text { da IE. }\end{array}$ & $\begin{array}{c}\text { Trajetória } \\
\text { organizacion } \\
\text { al e } \\
\text { experiência. }\end{array}$ & $\begin{array}{l}\text { Valoriza e alimenta } \\
\text { bons } \\
\text { relacionamentos. }\end{array}$ & $\begin{array}{c}\text { Cobrança por } \\
\text { resultados. Chefe como } \\
\text { agente integrador do } \\
\text { grupo. } \\
\text { Avaliação de } \\
\text { desempenho como } \\
\text { oportunidade. }\end{array}$ \\
\hline ChD2 & Funcional & $\begin{array}{l}\text { Limitados } \\
\text { à } \\
\text { legislação } \\
\text { da IE. }\end{array}$ & $\begin{array}{l}\text { Observação, } \\
\text { experiência, } \\
\text { aprender } \\
\text { com os } \\
\text { demais. }\end{array}$ & $\begin{array}{l}\text { Preferência aos } \\
\text { sistemas } \\
\text { informatizados a } \\
\text { depender de } \\
\text { pessoas. }\end{array}$ & $\begin{array}{l}\text { Os relacionamentos } \\
\text { interpessoais como } \\
\text { desafio. Avaliação de } \\
\text { desempenho como } \\
\text { problema. }\end{array}$ \\
\hline ChD3 & Funcional & $\begin{array}{l}\text { Advindos } \\
\text { de } \\
\text { aprendiza } \\
\text { gem } \\
\text { formal. }\end{array}$ & $\begin{array}{l}\text { Observação e } \\
\text { experiência. }\end{array}$ & $\begin{array}{l}\text { Mobiliza as pessoas } \\
\text { com poder } \\
\text { decisório para a } \\
\text { resolução de } \\
\text { problemas. } \\
\end{array}$ & $\begin{array}{c}\text { Os relacionamentos } \\
\text { interpessoais como } \\
\text { desafio. Avaliação de } \\
\text { desempenho como } \\
\text { problema. }\end{array}$ \\
\hline ChD4 & $\begin{array}{c}\text { Multidimensio } \\
\text { nal }\end{array}$ & $\begin{array}{l}\text { Limitados } \\
\text { à } \\
\text { legislação } \\
\text { da IE. }\end{array}$ & $\begin{array}{l}\text { Conhecer na } \\
\text { ação, } \\
\text { observação, } \\
\text { iniciativa } \\
\text { própria e } \\
\text { curiosidade. }\end{array}$ & $\begin{array}{l}\text { Não movimenta sua } \\
\text { rede de trabalho } \\
\text { consideravelmente. } \\
\text { Vale-se do mínimo } \\
\text { que lhe está } \\
\text { disponível. }\end{array}$ & $\begin{array}{c}\text { Imparcialidade para } \\
\text { superação de problemas } \\
\text { de relacionamento } \\
\text { interpessoal. Avaliação } \\
\text { de desempenho como } \\
\text { oportunidade. }\end{array}$ \\
\hline ChD5 & Funcional & $\begin{array}{c}\text { Não } \\
\text { necessário } \\
\text { s. }\end{array}$ & $\begin{array}{l}\text { Observação, } \\
\text { tentativa e } \\
\text { erro. }\end{array}$ & $\begin{array}{l}\text { Não movimenta sua } \\
\text { rede de trabalho } \\
\text { consideravelmente. } \\
\text { Vale-se do mínimo } \\
\text { que lhe está } \\
\text { disponível. }\end{array}$ & $\begin{array}{l}\text { Fuga aos conflitos. A } \\
\text { gestão limitada às } \\
\text { atividades acadêmico- } \\
\text { científicas. Avaliação } \\
\text { de desempenho como } \\
\text { problema. }\end{array}$ \\
\hline ChD6 & Funcional & $\begin{array}{c}\text { Não } \\
\text { necessário } \\
\text { s. }\end{array}$ & Observação. & $\begin{array}{l}\text { Não movimenta sua } \\
\text { rede de trabalho } \\
\text { consideravelmente. } \\
\text { Vale-se do mínimo } \\
\text { que lhe está } \\
\text { disponível. }\end{array}$ & $\begin{array}{l}\text { Os relacionamentos } \\
\text { interpessoais como } \\
\text { desafio. Avaliação de } \\
\text { desempenho como } \\
\text { problema. }\end{array}$ \\
\hline
\end{tabular}

Fonte: elaborado pelos autores a partir de dados primários (2013).

Os ChD1 e 4 possuem uma concepção multidimensional do seu trabalho e mobilizam mais recursos em cada componente em comparação aos demais. Como afirmado por Bitencourt et al. (2013), o conteúdo de cada componente depende diretamente da trajetória de cada pessoa, o que influencia seus saberes, suas ações e, talvez, sua concepção de trabalho.

Por sua vez, os ChD2 e 3 têm uma concepção funcional de seu trabalho, limitando a atuação do chefe a não muito mais que o cumprimento da descrição do cargo prevista para a 
função. No entanto, pelos relatos, observou-se que mobilizam mais saberes e recursos que os ChD4 e 5, os quais embora também tenham concepção funcionalista do que é ser chefe, mobilizam menos saberes, caracterizando um estilo laissez-faire de atuação, isto é, totalmente livre de interferências nas ações dos indivíduos que compõem o seu departamento.

As próximas duas seções apresentam dados encontrados nas entrevistas e que não vieram das perguntas-problema de pesquisa, porém não foram descartados, pois seu conteúdo também ajuda a construir a autoimagem dos professores-gestores entrevistados.

\subsection{O CONCEITO DE COMPETÊNCIA PARA O CHEFE DE DEPARTAMENTO DE ENSINO}

Os chefes de departamento confirmam a confusão terminológica do que sejam competências revelando visões distintas sobre seu significado. Para os ChD1 e 4, competências é um termo tão genérico que é complicado defini-lo. Mas, como no contexto atual de sua atuação os problemas de relacionamentos interpessoais são imperativos, para eles competências e ser um chefe de departamento competente é integrar as pessoas, é saber gerenciar os valores, as motivações, as atitudes dos funcionários do departamento e também dos parceiros envolvidos, como agências de fomento e sociedade civil, em prol dos objetivos gerais do departamento, da Universidade e dos grupos de interesse. Por sua vez, o entendimento atribuído a competências pelo $\mathrm{ChD} 2$ e 6 refere-se à aplicação de conhecimento e habilidades de acordo com requisitos e descrição do cargo, desprezando-se comportamentos pessoais em detrimento do desempenho superior ou cumprimento da legislação da Faculdade.

$\mathrm{O} \mathrm{ChD} 3$ acredita que competências sejam a capacidade de aplicar conhecimento e habilidades exigidos por seu cargo; porém, reconhece a importância dos comportamentos pessoais destacados pelos ChD1 e 4 e desprezados pelos ChD2 e 6 como atender as normativas e solicitações dos diversos grupos de interesse, cumprir reuniões, atender solicitações da reitoria, participar de reuniões e preocupar-se com o relacionamento humano.

Para o ChD5, pessoas não podem ser avaliadas por suas competências: "Não existem pessoas competentes e pessoas que não são competentes. [...] É diferente você falar vou montar um avião, que depende de um monte de conceitos técnicos, mecânicos, você consegue avaliar objetivamente, aí você consegue analisar competências”. Competência é entendida como um conjunto de atributos técnicos e científicos que o indivíduo possui necessários para se fazer sua avaliação de forma objetiva. O discurso do ChD5 demonstra que pessoas não possuem competências, senão habilidades, que são frutos da sua carga genética e 
influenciadas diretamente pelas oportunidades que seu contexto socioeconômico e cultural lhe propiciaram e que irão se manifestar na ação prática do indivíduo no trabalho.

\subsection{A QUEM CABE A GESTÃO UNIVERSITÁRIA}

O discurso de que cabe a quem a gestão dos departamentos de ensino apresentou resultados divergentes e interessantes. Os entrevistados ressaltaram todo o tempo que a UNESP não parece dar a devida atenção ao desenvolvimento formal dos chefes de departamento, uma vez que não há ações estruturadas de treinamento e educação para a gestão. Essa educação formal é necessária para otimizar os processos de aquisição, retenção e generalização de conhecimentos teóricos. Por isso, uma vez que a Universidade direciona a visão gerencial somente à concessão de gratificações salariais para que algum indivíduo assuma responsabilidades, os resultados não poderiam ser diferentes: todos os chefes de departamento reconhecem a importância da gratificação salarial, a qual é incorporada à remuneração básica do docente à razão de 1/10 por ano, como primeiro fator motivacional para se assumir a chefia departamental. Mesmo não havendo políticas de preocupação com a formação gerencial, os chefes percebem a importância da gestão e atribuem a ela o status de quarto pilar de sustentação da Universidade, junto com o ensino, a pesquisa e a extensão.

Claro está que outros fatores também foram identificados. Para os ChD1, 2 e 4, as funções gerenciais aproximam-se ao conceito de artistry proposto por Schön (1987), ou de uma combinação de ciência e arte (conhecimento especialista e tácito): “A gente vai com o que sabe e com o que não sabe, muitas vezes" (ChD4). "[...] trabalhar com a parte de gestão é uma parte bastante apaixonante" (ChD1). "Há pessoas que acabam desenvolvendo o gosto porque têm talento. É uma vocação" (ChD2). Por isso, o ChD2 sugere que a gestão, na Universidade, deve ficar a cargo de servidores públicos concursados com formação específica para tal, como os Administradores, porque "Gestão não é algo dos sonhos dos professores que assumem a carreira. É algo imposto", fazendo referência à cobrança da Universidade das atividades de gestão como requisito para progressão na carreira docente. Na revisão teórica de Smith (2002), muitos docentes se veem com a missão de promover sua área de atuação e incentivar os demais a pesquisar, por isso, não querem ser gestores. Por sua vez, uma minoria acredita que a natureza da educação e da gestão de ensino superior mudou e que, assim, habilidades gerenciais são necessárias e devem ser desenvolvidas. 


\section{CONSIDERAÇÕES FINAIS}

Este trabalho se propôs a conhecer como professores da Faculdade de Odontologia de Araçatuba/UNESP desenvolvem suas competências gerenciais para atuarem como chefes de departamentos de ensino. Para tal, buscou-se saber o que esses professores entendem por um chefe de departamento competente, ou seja, que concepção dão ao seu trabalho e, consequentemente, quais conhecimentos mobilizam para a prática da função.

A concepção dada ao trabalho é, em sua essência, funcional, isto é, supervisionar e controlar atributos técnicos inerentes à função, atuando como instrumentos burocráticos da gestão da Faculdade e da Universidade. As concepções dadas ao seu trabalho e à ausência de políticas de formação gerencial para estes docentes na Universidade explicam os saberes que esses chefes mobilizam para a sua prática profissional.

Dessa forma, este estudo nos perturba a ponto de perguntar se não caberia um olhar mais cuidadoso da Universidade com a atuação e desenvolvimento gerencial deste professor sobrecarregado com cobranças e que tem sobre os ombros a responsabilidade de garantir os resultados de sua equipe de professores, uma vez que muitas das políticas de distribuição de recursos na Universidade dependem da produção científica dos departamentos. Os resultados apontam que não há falta de consciência dos docentes sobre a sua atuação gerencial, mas que são as insuficiências estruturais como falta de espaço para a discussão e reflexão sobre o papel do chefe de departamento que faz com que sua função se limite a de um burocrata.

A visão de Kerr (2005, p. 46) de que a universidade "é uma metrópole infinita de variedade" faz perceber claramente que à figura do professor, somou-se a de administrador, consultor, pesquisador, fomentador de recursos internos e externos, entre outras que tornaram o lecionar a atividade menos fundamental. Com o prestígio atribuído em grandes proporções à pesquisa e à pós-graduação, a atividade de gestão, assim como o ensino na graduação, têm-se limitado aos interesses e responsabilidade de minorias ativas de docentes. Com a rápida velocidade das mudanças que as universidades afrontam, os estudos das competências do professor-gestor não consegue acompanhá-las.

Há grande preocupação neste cenário acadêmico considerando que, embora tenham se passado tantos anos desde o estudo de Moses (1985) e Smith (2002) e que não há pesquisas suficientes sobre o assunto no Brasil, ainda não se nota evolução no perfil dos chefes de departamento, o que pode ser uma inquietação diante da demanda de preocupações às quais estes professores estão submetidos. Este panorama deve se agravar, pois os métodos de gestão 
e conduta das universidades são os mais conservadores e tendem a permanecer deste modo (KERR, 2005). Portanto, a mudança na concepção do trabalho sobre o que é ser chefe de departamento seria a forma mais básica de desenvolvimento de competências (SANDBERG, 2000) desses professores para atuarem como gestor universitário, por isso, os próprios entrevistados cobraram da universidade treinamentos para a função de chefe, sobretudo a valorização da função gerencial, pois a entendem como sendo um dos pilares de sustentação da instituição, como o são o ensino, a pesquisa e a extensão. Muito embora já se saiba que programas de treinamento contribuem pouco para a aprendizagem e mudança de atitudes (CLOSS; ANTONELLO, 2011). Talvez fosse urgente a construção de caminhos que conduzissem a Universidade a responder como estes docentes deveriam enxergar suas funções de chefe de departamento uma vez que a universidade moderna volta-se para o mundo externo, globalizado, e não mais se encerra em seus próprios muros. Este trabalho pode ser o início deste caminho.

Uma vez que o conceito de competência é polissêmico e uma construção social, sugere-se que pesquisas futuras continuem a lançar luzes sobre a atuação gerencial do professor-gestor e que esse profissional seja objeto de estudos em universidades públicas e privadas. Estudos qualitativos poderiam dar suporte aos achados deste trabalho ao buscar compreender relações entre a história de vida do professor e suas orientações para querer tornar-se gestor. Também, em que medida os aspectos levantados neste estudo têm suas raízes na própria estrutura organizacional da universidade, na sua cultura, política e pressupostos pedagógicos e, assim, como podem influenciar a formação e atuação do professor-gestor e a própria instituição de ensino. Espera-se que este estudo seja uma contribuição para o debate sobre as competências de chefes de departamento nas universidades dentro do modelo de ciclo de competências proposto por Sandberg (2000).

\section{REFERÊNCIAS}

BITENCOURT, C.C.; AZEVEDO, D.; FROEHLICH, C. Na trilha das competências: caminhos possíveis no cenário das organizações. Porto Alegre: Bookman, 2013.

BOYATZIS, R. E. Competence and performance. In: The competent manager. New York: John Wiley \& Sons, 1982.

CLOSS, L. Q.; ANTONELLO, C. S. Ampliando as fronteiras da educação gerencial: é possível uma refelxão crítica? In: ANTONELLO, C. S.; GODOY, A. S. (org.) Aprendizagem organizacional no Brasil. Porto Alegre: Bookman, 2011. p. 399-421. 
CUNLIFFE, A.L. On Becoming a Critically Reflexive Practitioner. Journal of Management Education, v.28, p. 407-426, 2004.

DELAMARE-LE DEIST, F.; WINTERTON, J. What is competence? Human resource development international, v. 8, n.1, March, p. 27-46, 2005.

ÉSTHER, A. B.; SILVA, F. T.; MELO, B. S. A Identidade Gerencial de Chefes de Departamento de Universidades Federais em Minas Gerais. Gerais: Revista Interinstitucional de Psicologia, v.3, n.2, p. 213-222, 2010.

FLICK, U. Introdução à pesquisa qualitativa. $3^{\mathrm{a}}$. ed. Porto Alegre: Artmed, 2009.

FLORES, J. G. Análisis de datos cualitativos: aplicaciones a la investigación educativa. Barcelona: PPU, 1994. p. 7-107.

GEPHART, R. From the editors: Qualitative Research and the Academy of Management Journal. Academy of Management Journal, v.47, n. 4, p. 454-462, 2004.

GHERARDI, S.; NICOLINI, D. The Sociological Foundations of Organizational Learning. In: DIERKES, M. et al. (Org.) Handbook of Organizational Learning and Knowledge. Oxford: Oxford University Press, p. 35-60, 2001.

KERR, C. Os usos da universidade. 15ª . ed. Brasília: Editora UnB, 2005.

KOLB, D. Experiential Learning: experience as the source of learning and development. New Jersey: Prentice Hall, 1984.

LAZARIN, R. C. R. A Avaliação de Desempenho: A percepção e a ação no exercício profissional. Universidade do Mato Grosso, 2008. Acesso em 03.Mar.2013.

LE BOTERF, G. Desenvolvendo a competência dos profissionais. Porto Alegre: Artmed, 2003.

LEITE, I. C. B. V. O aprendizado da função gerencial por meio da experiência. In:

ANTONELlO, C. S.; GODOY, A. S. (org.) Aprendizagem organizacional no Brasil. Porto Alegre: Bookman, 2011. p.201-224.

MARRA, A. V.; MELO, M. C. O. L. A prática social de gerentes universitários em uma instituição pública. Rev. adm. contemp. v. 9, n. 3, 2005.

McKENNA, S. Storytelling and "real" management competence. Journal of Workplace Learning. Bradford, v. 11, n.3, 1999.

McCLELLAND, D. C. Testing for Competence rather than intelligence. American Psychologist, v. 28, n. 1, 1973.

MERRIAN, S. B. Qualitative research and case study applications in education. San Francisco: Jossey-Bass, 1998. 
MOSES, I. The Role of Head of Department in the Pursuit of Excellence. Higher Education, v. 14, p. 337-354, 1985.

MOURA, M. C. C.; BITENCOURT, C.C. A articulação entre estratégia e o desenvolvimento de competências gerenciais. RAE, v. 5, n. 1, jan/jun 1996.

ODERICH, C. Gestão de competências gerenciais: noções e processos de desenvolvimento. In: RUAS, R.; ANTONELLO, C. S.; BOFF, L. H. (org.) Aprendizagem organizacional e competências. Porto Alegre: Bookman. 2008.

PARRY, S. B. The quest for competencies. Training and Development. July, 1996.

RUAS, R. Desenvolvimento de competências gerenciais e a contribuição da aprendizagem organizacional. In: FLEURY, M.T. \& OLIVEIRA Jr. M. (org.) Gestão estratégica do conhecimento. São Paulo: Atlas, 2001.

SANDBERG, J. Understanding human competence at work: an interpretative approach. Academy of Management Journal, v. 43, n. 1, p. 9-25, 2000.

; DALL'ALBA, G. Refraiming competence develepoment at work. In:

CASTLETON, G.; GERBER, R.; PILLAY, H. (orgs.) Improving Workplace Learning. Nova: New York, 2006, p. 107-121.

SCHÖN, D. Educating the Reflective Practitioner. San Francisco: Jossey-Bass, 1987.

SILVA, F. M. V.; CUNHA, C. J. C. A. Tornar-se líder universitário: o significado das relações interpessoais. In: VII EnEO/ANPAD, 2012, Curitiba. Anais do VII EnEO, 2012.

SILVA, M. A.; MORAES, L. V. S.; MARTINS, E. S.. A aprendizagem gerencial dos professores que se tornam dirigentes universitários: o caso da UDESC. In: XXVII Encontro da ANPAD, 2003, Atibaia. Anais do XXVII EnANPAD, 2003.

SMITH, R. The Role of the University Head of Department: a Survey of two British Universities. Educational Management \& Administration, v. 30, n. 3, p. 293-312, 2002.

SPENCER, L.; SPENCER, S. Competence at work: a model of superior performance. New York: Wiley, 1993.

WHITE, R. Motivation reconsidered: the concept of competence. Psychological Review, v. 66, p. 279-333, 1959. 